\title{
Prevalence of different HIV-1 subtypes in an urban clinic in Madrid
}

\section{J C Martín, A Holguín, V Soriano}

C oncern about the implications of the growing proportion of circulating HIV variants in Western Europe and North America has been increasing over the past few years. ${ }^{1-3}$ Diagnostic procedures including viral load determinations and drug resistance testing may either fail or not be reliable when specimens from subjects carrying HIV-1 non-B subtypes are examined. Moreover, the efficacy of different antiretroviral compounds against non- $\mathrm{B}$ viruses is not well known. ${ }^{5}$ Finally, the biological consequences of the new generation of recombinant HIV variants is uncertain, but hypothetically it may lead to the emergence of more virulent viruses, which might impose and drive the future epidemic in a community.

The introduction of non- $\mathrm{B}$ viruses into Western Europe and North America seems to be mediated by immigrants from regions where other HIV-1 variants are prevalent. ${ }^{6}$ In addition, natives who had been exposed to HIV in those regions represent an alternative source of non-B variants for the developed world

Madrid is an endemic area for HIV From a total population of around five million, nearly 8000 individuals have suffered AIDS defining conditions so far, and around 35000 people are estimated to be alive with HIV infection. The number of immigrants has increased dramatically in the past 5 years, the largest proportion coming from Africa and South America.

In order to assess the current extent of HIV-1 non-B variants, all HIV infected people attending a reference HIV/AIDS centre located in Madrid over a 1 year period (June 1999 to June 2000) were examined. Only one out of four similar outclinics belonging to the Instituto de Salud Carlos III was selected for this purpose. A total of 902 HIV seropositive individuals were seen during the study period. Genetic subtype characterisation was performed on plasma specimens belonging to all subjects considered to be at risk for infection with non-B HIV variants as well as a control group of 145 native individuals without apparent risk for exposure to non-B viruses. People considered to be at risk for carrying non-B variants included all immigrants, as well as natives who admitted having had HIV risk practices in non-B endemic regions or with subjects originating in those regions. Moreover, subjects experiencing unexpected CD4 falls in spite of either low or undetectable plasma viraemia were tested. HIV-l subtype characterisation was carried out by genetic sequence analysis of nested polymerase chain reaction amplicons representing the entire 297 bp HIV-1 protease gene, as described elsewhere. ${ }^{3}$

A total of 73 individuals (overall prevalence $8.1 \%$ ) were found to be at risk for carrying non-B subtypes. Table 1 summarises their main characteristics. Twenty eight (38.4\%) of them were African immigrants. In contrast with people without risk for infection with non-B viruses, people at risk had acquired HIV infection through more frequent sexual contact $(43.2 \%$ versus $83.6 \%, \mathrm{p}<0.01)$.

Twenty seven individuals were found to be infected with HIV-l non-B sub-

Table 1 Main epidemiological features of the study population

\begin{tabular}{lllll}
\hline & & \multicolumn{2}{l}{ At risk for infection with non-B subtypes } \\
\cline { 3 - 5 } & No risk & Non-Africans & Africans & Total \\
\hline Number & 829 & 45 & 28 & 73 \\
Sex (male) & 642 & 35 & 13 & 48 \\
Mean age (years) (SD) & $38(7)$ & $40(6)$ & $37(6)$ & $38(6)$ \\
Risk group & & & & \\
Injecting drug users & 452 & 10 & 0 & 10 \\
$\quad$ Homosexuals & 262 & 26 & 2 & 28 \\
$\quad$ Heterosexuals & 96 & 9 & 24 & 33 \\
$\quad$ Transfusion & 3 & 0 & 0 & 0 \\
$\quad$ Unknown & 14 & 0 & 2 & 2 \\
Non-B subtypes & $0 / 145$ & $7(15.5 \%)$ & $20(71.4 \%)$ & $27(37 \%)$ \\
\hline
\end{tabular}

types, which represented $37 \%$ of those considered at risk for infection with these variants. When African immigrants were considered separately, $71.4 \%$ of them were found to be infected with non-B subtypes. Of note, non-B subtypes were absent in all natives belonging to the control group as well as in all 14 with unexplained CD4 falls.

The results of this study suggest that the prevalence of infection with HIV-1 non-B subtypes among HIV infected people in Madrid is low (estimated overall prevalence $3 \%$ ). However, up to $71.4 \%$ of African immigrants carry non-B viruses. Therefore, HIV subtyping should be requested from all HIV infected African immigrants, and testing might be recommended for natives admitting having had risky behaviour overseas.

Sex Transm Inf 2002;78:e

www.sextransinf.com/cgi/content/full/78/1/el

\section{Authors' affiliations}

J C Martín, A Holguín, V Soriano, Service of Infectious Diseases, Instituto de Salud Carlos III, Madrid, Spain

Correspondence to: Dr Vincent Soriano, Service of Infectious Diseases, Instituto de Salud Carlos III, C/ Sinesio Delgado 10, 28029 Madrid, Spain; vsoriano@dragonet.es

Accepted for publication 30 August 2001

\section{REFERENCES}

1 Van Hooff F, Loveday C, Burke A, et al Characterization of HIV-1 non-B subtype prevalence in a population attending a London HIV/AIDS outpatient clinic. AIDS 2000;14:109.

2 Couturier E, Damond F, Roques P, et al. HIV-1 diversity in France: 1996-1998. AIDS 2000; 14:289-96.

3 Pieniazek D, Rayfield M, Hu D, et al. Protease sequences from HIV-1 group $M$ subtypes A-H reveal distinct amino acid mutation patterns associated with protease resistance in protease inhibitor naive individuals worldwide. AIDS 2000;14:1489-95.

4 Holguín A, Soriano V. Prevalence of HIV-1 non-B subtypes in foreigners living in Madrid and performance of the Amplicor HIV-1 Monitor version 1.0 vs the new automated version 1.5 (COBAS). J Clin Microbiol $2001 ; 39: 1850-4$

5 Palmer S, Alaeus A, Albert J, et al. Drug susceptibility of subtypes $A, B, C, D$, and $E$ HIV-1 primary isolates. AIDS Res Hum Retroviruses 1998;14:157-62

6 Holguín A, Rodés B, Dietrich U, et al. Protease gene analysis of HIV type 1 non-B subtypes in Spain. AIDS Res Hum Retroviruses 2000; 16:1395-403. 